\title{
ANALISIS PENDAPATAN USAHATANI SAYURAN DI KELURAHAN LAMBANAPU KECAMATAN KAMBERA KABUPATEN SUMBA TIMUR
}

\section{ANALYSIS OF INCOME FARMING OF VEGETABLES IN LAMBANAPU VILLAGE KAMBERA SUB-DISTRICT SUMBA TIMUR DISTRICT}

\section{Elsa Christin Saragih}

Program Studi Agribisnis Universitas Kristen Wira Wacana Sumba Jl. R. Suprapto No. 35 Waingapu, Kabupaten Sumba Timur - NTT

E-mail: elsacsaragih@unkriswina.ac.id

(Diterima 3-12-2020; Disetujui 2-1-2021)

\begin{abstract}
ABSTRAK
Sayuran merupakan salah satu komoditas tanaman hortikultura yang berperan penting sebagai sumber pendapatan yang dapat memenuhi kebutuhan hidup petani. Analisis pendapatan dan efisiensi usahatani merupakan awal dalam penentuan sikap untuk melakukan usahatani sayursayuran dan umumnya petani sayuran di Kelurahan Lambanapu belum pernah melakukan perhitungan pendapatan maupun besarnya biaya dalam proses usahataninya dengan terperinci. Penelitian ini bertujuan untuk untuk menganalisis pendapatan dan efisiensi usahatani petani sayuran di Kelurahan Lambanapu. Penelitian dilaksanakan pada bulan Mei hingga Juni 2020 di Kelurahan Lambanapu, Kecamatan Kambera, Kabupaten Sumba Timur. Jenis penelitian deskriptif kuantitatif. Dengan menggunakan rumus Slovin ditentukan sampel sebanyak 43 petani. Penelitian ini menggunakan analisis pendapatan dan $\mathrm{R} / \mathrm{C}$ ratio. Hasil analisis pendapatan menunjukkan bahwa pendapatan petani sayuran di Kelurahan Lambanapu selama satu musim tanam terakhir sudah menguntungkan. Pendapatan usahatani atas biaya tunai sayuran per $1000 \mathrm{~m}^{2}$ pada musim tanam Mei-Juni 2020 mencapai Rp 9.377.295/MT/petani dan pendapatan atas biaya diperhitungkan sebesar Rp 8.079.380/MT/petani. hasil analisis efisiensi kegiatan usahatani sayuran di Kelurahan Lambanapu sudah efisien karena rasio $\mathrm{R} / \mathrm{C}$ lebih dari satu $(\mathrm{RC}>1)$, yaitu sebesar 5,53 untuk biaya tunai dan 3,37 untuk biaya yang diperhitungkan, yang berarti kegiatan usahatani sayuran ini layak untuk dikembangkan karena menguntungkan secara ekonomis.
\end{abstract}

Kata kunci: Biaya diperhitungkan, Biaya tunai, Pendapatan, R/C Ratio, Usahatan sayuran

\section{ABSTRACT}

Vegetables are one of the horticultural crops that play an important role as a source of income that can meet the needs of farmers. The analysis of income and farming efficiency is the beginning in determining the attitude to do vegetable farming and in general, vegetable farmers in Lambanapu Village have never calculated the income or the amount of costs in the farming process in detail. This study aims to analyze the income and farming efficiency of vegetable farmers in Lambanapu Village. The research was conducted from May to June 2020 in Lambanapu Village, Kambera SubDistrict, East Sumba Regency. This type of descriptive quantitative research. Using the Slovin formula, a sample of 43 farmers was determined. This research uses income analysis and $R / C$ ratio. The results of the income analysis show that the income of vegetable farmers in Lambanapu Village during the last one planting season has been profitable. Farm income from cash costs for vegetables per $1000 \mathrm{~m} 2$ in the planting season from May to June 2020 is Rp. 9,377,295, - / farmer and the cost of income is calculated at Rp. 8,079,380, - / farmer. The results of the analysis of the efficiency of vegetable farming activities in Lambanapu Village are efficient because the $R / C$ ratio is more than one ( $R C>1$ ), which is 5.53 for cash costs and 3.37 for calculated costs, which means that vegetable farming is feasible for developed because it is economically profitable.

Keywords: Calculated costs, Cash costs, Iincome, $R$ / C ratio, Vegetable farming 


\section{ANALISIS PENDAPATAN USAHATANI SAYURAN DI KELURAHAN LAMBANAPU \\ KECAMATAN KAMBERA SUMBA TIMUR \\ Elsa Christin Saragih}

\section{PENDAHULUAN}

Hortikultura merupakan salah satu subsektor pertanian di Indonesia yang cukup potensial. Letaknya yang tepat berada di garis khatulistiwa menjadikan Indonesia memiliki iklim tropis yang cocok bagi pengembangan tanaman hortikultura. Subsektor tanaman hortikultura terdiri dari sayuran, buahbuahan, tanaman hias dan biofarmaka. Subsektor hortikultura memberikan kontribusi sebesar 1,44 \% dari Produk Domestik Bruto (PDB) Indonesia, dan memberikan kontribusi sekitar $11 \%$ dari total nilai tambah sektor pertanian yangmencapai 1.785 trilyun rupiah (BPS, 2018). Selain sebagai sumber pendapatan negara, komoditas hortikultura bagi manusia juga bermanfaat sebagai sumber pangan dan gizi, sumber pendapatan keluarga, serta sebagai penyangga kelestarian alam (Arief, 1990).

Sayuran merupakan salah satu komoditas tanaman hortikultura yang bermanfaat sebagai sumber vitamin, mineral dan serat bagi manusia. Sayuran merupakan tumbuhan yang mengandung kadar air yang tinggi yang bisa dikonsumsi dalam keadaan mentah (segar) maupun dibuat menjadi olahan pangan terlebih dahulu. Sayuran berperan penting sebagai sumber pendapatan yang dapat memenuhi kebutuhan hidup petani. Pada umumnya sayuran merupakan tanaman yang berumur pendek sehingga cepat dipanen, pembudidayaannya menggunakan teknologi yang sederhana dan hasilnya dapat diserap pasar dengan cepat (Edi \& Bobihoe, 2010).

Seiring peningkatan pengetahuan dan pendidikan masyarakat meningkat juga kesadaran masyarakat akan pentingnya mutu makanan termasuk sayuran. Menurut Hermina \& Prihatini (2016), proporsi jumlah penduduk perkotaan maupun pedesaan dalam mengkonsumsi sayuran hampir sama. Untuk menjawab kebutuhan ini pasar harus bisa menyediakan sayuran segar setiap hari. Dengan demikian jelaslah peluang bisnis sayuran cukup besar dan menjanjikan bagi para petani.

Kelurahan Lambanapu merupakan salah satu pemasok sayuran ke pasarpasar yang ada di kota Waingapu yang merupakan ibukota Kabupaten Sumba Timur. Komoditas sayuran yang paling banyak diusahakan oleh petani di Lambanapu antara lain: bayam, kangkung, sawi, kubis, kacang panjang, terong, tomat dan bawang. Petani sayuran di Kelurahan Lambanapu menanam sayur dengan sistem yang bermacam-macam. Sebagian petani melakukan sistem 
penanaman rotasi, dimana setelah melakukan pemanenan satu jenis sayuran kemudian lahan ditanami jenis sayuran yang lain. Namun sebagian besar petani di Lambanapu melakukan sistem polikultur, yaitu petani menanam berbagai macam sayuran pada satu lahan pada saat yang bersamaan. Sawi, kangkung dan bayam merupakan tiga jenis komoditas sayuran yang selalu ditanami secara polikultur oleh petani sayuran di Lambanapu.

Dalam melakukan usahatani, analisis pendapatan merupakan awal dalam penentuan sikap untuk melakukan usahatani sayur-sayuran (Normansyah, et al, 2014). Analisis perhitungan pendapatan usahatani dilakukan untuk memberikan gambaran mengenai produksi dan harga jual yang akan mempengaruhi pendapatan petani dalam berusahatani sayuran (Azzura, et al, 2017). Walaupun demikian, umumnya petani sayuran di Kelurahan Lambanapu belum pernah melakukan perhitungan pendapatan maupun besarnya biaya dalam proses usahataninya dengan terperinci.

Pendapatan yang cukup besar yang diperoleh petani dalam usahatani tidak ada artinya apabila diperoleh dengan pengeluaran biaya produksi yang cukup besar juga. Petani harus bisa menekan biaya produksi dalam usahataninya agar rasionya dibandingkan dengan pendapatan yang diterima cukup lebar. Menurut Soekartawi, et al (1985) semakin besar rasio yang didapatkan antara pendapatan dan biaya, maka pilihan petani dalam penggunaan sumberdaya yang dilakukan dalam kegiatan usahataninya semakin tepat. Berdasarkan rasio ini dapat dianalisis efisiensi pendapatan usahataninya.

Berdasarkan uraian di atas, maka dilakukan penelitian untuk menganalisis pendapatan dan efisiensi usahatani petani sayuran di Kelurahan Lambanapu.

\section{METODE PENELITIAN}

Penelitian ini akan dilaksanakan di Kelurahan Lambanapu, Kecamatan Kambera, Kabupaten Sumba Timur. Penentuan lokasi penelitian dilakukan dengan sengaja (purposive), dengan pertimbangan bahwa Kelurahan Lambanapu merupakan salah satu wilayah penghasil sayuran di Kecamatan Kambera. Penelitian dilaksanakan selama dua bulan yaitu dimulai pada bulan Mei sampai bulan Juni 2020. Jenis penelitian deskriptif kuantitatif.

Pada penelitian ini, variabel yang diamati adalah data dan informasi 


\section{ANALISIS PENDAPATAN USAHATANI SAYURAN DI KELURAHAN LAMBANAPU \\ KECAMATAN KAMBERA SUMBA TIMUR \\ Elsa Christin Saragih}

usahatani sayuran yang diusahakan oleh petani. Variabel-veriabel yang digunkan dalam penelitian ini, antara lain:

1. Petani sayuran adalah petani yang membudidayakan sayuran (sawi, bayam, kangkung) di Kelurahan Lambanapu selama minimal 3 musim tanam terakhir.

2. Luas lahan garapan adalah luas areal usahatani sayuran yang dikuasai petani untuk melakukan usahatani sayuran dalam satuan meter persegi $\left(\mathrm{m}^{2}\right)$.

3. Harga jual adalah besaran uang yang harus dibayarkan oleh konsumen untuk membeli sayuran dari petani dalam satuan rupiah per ikat (Rp/ikat).

4. Biaya tunai adalah besarnya nilai uang tunai yang dikeluarkan petani untuk membeli barang dan jasa bagi usahatani dalam satuan rupiah $(\mathrm{Rp})$

5. Biaya yang diperhitungkan adalah pengeluaran untuk pemakaian input milik sendiri dan pemakaian upah tenaga kerja dalam keluarga, berdasarkan tingkat upah yang berlaku dalam satuan rupiah $(\mathrm{Rp})$

6. Biaya total merupakan penjumlahan dari biaya tunai dan biaya yang diperhitungkan dalam satuan rupiah (Rp)
7. Penerimaan usahatani adalah nilai uang yang diterima dari penjualan produk usahatani dalam satuan rupiah (Rp)

8. Pendapatan usahatani adalah total hasil penerimaan dikurangi total biaya yang dikeluarkan petani dalam mengusahakan sayuran dalam satuan rupiah $(\mathrm{Rp})$.

9. Tenaga kerja adalah manusia yang digunakan dalam proses produksi dari pengolahan lahan hingga pemanenan. Tenaga kerja ini dibedakan menjadi tenaga kerja dalam keluarga (TKDK) dan luar keluarga (TKLK). Seluruh tenaga kerja disetarakan dengan Hari Kerja Setara Pria (HKSP) dengan lama kerja tujuh jam per hari.

Petani yang dijadikan sampel dalam penelitian ini adalah petani sayuran yang membudidayakan sayuran sawi, bayam dan kangkung di Kelurahan Lambanapu. Dengan menggunakan rumus Slovin ditentukan sampel sebanyak 43 petani. Teknik penarikan sampel dilakukan dengan teknik simple random sampling, dengan pertimbangan bahwa kondisi usahatani sayuran di Kelurahan Lambanapu seragam atau homogen dalam teknik budidaya.

Kegiatan pengumpulan data dalam penelitian ini dilakukan dengan survey 
dan wawancara langsung kepada petani. Teknik wawancara yang dilakukan dengan menggunakan kuesioner (angket) yang berisi seperangkat pertanyaan atau pernyataan berdasarkan data-data yang dibutuhkan dalam penelitian yang harus dijawab oleh responden.

Pendapatan usahatani dapat diperoleh melalui perhitungan selisih penerimaan usahatani dan pengeluaran total usahatani (Soekartawi et al. 1985). Penerimaan total usahatani merupakan nilai produksi dari usahatani, yaitu harga jual dari produksi dikalikan total produksi, dengan rumus:

$\mathrm{TR}=\mathrm{P} . \mathrm{Q}$

Dimana:

$\mathrm{TR}=$ total revenue $($ penjumlahan penerimaan tunai dan non tunai dalam rupiah)

$\mathrm{P}=$ harga output (harga sayur dalam $\mathrm{Rp)}$

$\mathrm{Q}=$ jumlah output (produk sayur dalam ikat)

Pendapatan tunai usahatani (farm net cash flow) adalah selisih antara penerimaan tunai usahatani dan pengeluaran tunai usahatani (Soekartawi et al. 1985). Perhitungan pendapatan usahatani atas biaya tunai dapat dituliskan sebagai berikut:

$$
\mathrm{Y}_{\text {tunai }}=\text { Penerimaan tunai }-\mathrm{BTU}
$$

Dimana:

$\mathrm{Y}_{\text {tunai }}=$ Pendapatan tunai $(\mathrm{Rp})$

$\mathrm{BTU}=$ Biaya tunai $(\mathrm{Rp})$

Pendapatan total usahatani (total farm income) merupakan selisih antara penerimaan total dengan biaya total, dengan rumus:

$$
\mathrm{Y}_{\text {total }}=\mathrm{TR}-\mathrm{BTO}
$$

\section{Keterangan:}

$$
\begin{aligned}
\mathrm{Y}_{\text {total }}= & \text { pendapatan total }(\mathrm{Rp}) \\
\mathrm{BTO}= & \text { biaya total ( penjumlahan biaya } \\
& \text { tunai dan biaya non tunai } \\
& \text { dalam } \mathrm{Rp})
\end{aligned}
$$

Pendapatan yang besar tidak selalu menunjukkan efisiensi yang tinggi. Oleh karena itu analisis pendapatan selalu diikuti dengan pengukuran efisiensi. $\mathrm{R} / \mathrm{C}$ merupakan salah satu ukuran efisiensi yang menggambarkan penerimaan untuk tiap rupiah yang dikeluarkan (revenue cost ratio). $\mathrm{R} / \mathrm{C}$ rasio yang dihitung dalam analisis ini terdiri dari $\mathrm{R} / \mathrm{C}$ atas biaya tunai dan $\mathrm{R} / \mathrm{C}$ atas biaya total, yang secara sederhana dapat diturunkan dari rumus:

$$
\begin{aligned}
& \mathrm{R} / \mathrm{C}_{\text {tunai }}=\frac{\text { penerimaan total }}{\text { biaya tunai }} \\
& \mathrm{R} / \mathrm{C}_{\text {total }}=\frac{\text { penerimaan total }}{\text { biaya total }}
\end{aligned}
$$

Dimana:

$\mathrm{R}=$ revenue atau penerimaan $(\mathrm{Rp})$

$\mathrm{C}=$ cost atau pengeluaran $(\mathrm{Rp})$ 


\section{ANALISIS PENDAPATAN USAHATANI SAYURAN DI KELURAHAN LAMBANAPU \\ KECAMATAN KAMBERA SUMBA TIMUR \\ Elsa Christin Saragih}

Nilai $\quad \mathrm{R} / \mathrm{C} \quad$ secara teoritis menunjukkan bahwa setiap satu rupiah biaya yang dikeluarkan akan memperoleh penerimaan, jika $\mathrm{R} / \mathrm{C}>1$ maka kegiatan usahatani efisien untuk dijalankan. Akan tetapi apabila $\mathrm{R} / \mathrm{C}<1$ maka kegiatan usaha tani tidak efisien untuk dijalankan.

\section{HASIL DAN PEMBAHASAN}

\section{Karakteristik Responden}

Mayoritas petani responden petani sayuran di Kelurahan Lambanapu berada pada usia produktif yaitu berusia lebih 15 tahun dan kurang dari 65 tahun. Umur responden petani sayuran di lokasi penelitian didominasi oleh responden yang berada pada rentang usia 30-39 tahun $(34,88 \%)$ dan $40-49$ tahun $(34,88 \%)$ dengan rata-rata usia responden adalah 43 tahun. Reponden dengan rentang usia di bawah 30 sangat sedikit yaitu sebanyak 4,65\%, hal ini mengindikasikan bahwa minat tenaga usia muda di Kelurahan Lambanapu untuk berkecimpung dalam usaha pertanian sangat rendah.

Responden yang merupakan petani sayuran di Kelurahan Lambanapu memiliki tingkat pendidikan yang beragam, akan tetapi tingkat pendidikan formal reponden sebagian besar rendah. Sebanyak

$$
60,47 \% \quad \text { responden }
$$

berpendidikan setingkat SD, bahkan masih ada responden yang tidak bersekolah yaitu sebanyak 4,65\%. Hal ini disebabkan oleh kondisi sosial ekonomi masyarakat di daerah tersebut berada pada kategori rendah sehingga tidak mampu untuk menempuh jenjang pendidikan yang lebih tinggi.

Lama pengalaman usahatani responden petani sayuran di lokasi penelitian sebagian besar lebih dari 15 tahun $(51,16 \%)$. Rata-rata lama pengalaman responden yaitu selama `19 tahun. Hal ini menunjukkan bahwa responden memiliki pengalaman yang baik karena cukup lama menggeluti usahatani. Lama pengalaman berusahatani dapat mempengaruhi tingkat adaptasi petani terhadap berbagai risiko dan perubahan lingkungan untuk mempertahankan keberlangsungan aktivitas usahatani yang dijalankannya.

Jumlah tanggungan keluarga responden responden petani sayuran yang terbanyak adalah 4-7 orang $(69,77 \%)$, dengan rata-rata jumlah tanggungan sebanyak 6 orang untuk setiap keluarga. Besarnya jumlah tanggungan keluarga akan mempengaruhi pengeluaran belanja rumah tangga terutama untuk pengeluran konsumsi. Akan tetapi di sisi lain jumlah anggota keluarga yang banyak 
memberikan keuntungan bagi usahatani, apabila anggota keluarga berada pada usia produktif maka dapat terlibat dalam kegiatan usaha sebagai tenaga kerja tanpa harus mengeluarkan biaya.

Luas lahan yang dimiliki responden sebagian besar mempunyai luas lahan yang sempit yaitu pada kisaran kurang dari $500 \mathrm{~m}^{2}$ yaitu sebanyak $79,07 \%$. Petani sayuran rata-rata menggarap lahan seluas $656 \mathrm{~m}^{2}$. Hal ini menunjukkan bahwa umumnya para petani disana menjalankan usahatani dalam skala kecil. Oleh karena itu, apabila petani ingin meningkatkan produktivitasnya maka mereka harus melakukan intensifikasi pertanian.

Status kepemilikan lahan reponden sebanyak $90,70 \%$ adalah milik pribadi dan sisanya yaitu sebanyak 9,30\% merupakan lahan sewa. Dalam hal ini dapat disimpulkan bahwa mayoritas responden merupakan petani pemilik, yang berarti bahwa petani dapat mengelola lahannya tanpa terbebani biaya penggunaan lahan seperti sewa ataupun bagi hasil. Biaya sewa lahan sendiri dapat mengurangi pendapatan petani dalam usahataninya.

\section{Analisis Pendapatan Usahatani Sayuran}

\section{Analisis Penerimaan}

Penerimaan usahatani adalah perkalian antara total produksi yang diperoleh petani dengan harga jual (Soekartawi, et al, 1985) Penerimaan usahatani sayuran di Kelurahan Lambanapu diperoleh dari jumlah penerimaan usahatani dari tiga jenis sayuran yaitu sawi, kangkung dan bayam selama 1 periode musim tanam (Mei-Juni 2020). Penerimaan rata-rata usahatani sayuran selama musim tanam terakhir per $1000 \mathrm{~m}^{2}$ dapat dilihat pada Tabel 1.

Tabel 1. Penerimaan Rata-Rata Usahatani Sayuran Per Musim Tanam di Kelurahan Lambanapu Mei-Juni 2019

\begin{tabular}{llcrr}
\hline \multicolumn{1}{c}{ Sayuran } & Harga $(\mathrm{Rp})$ & Produksi (ikat) & $\begin{array}{c}\text { Penerimaan } \\
(\mathrm{Rp} / \mathrm{MT})\end{array}$ & $\begin{array}{c}\text { Penerimaan per } \\
1000 \mathrm{~m}^{2}\end{array}$ \\
\hline 1. Sawi & $5.000 / 6$ ikat & 1.274 & 910.050 & 3.690 .401 \\
2. Kangkung & $5.000 / 8$ ikat & 1.585 & 990.407 & 4.771 .709 \\
3. Bayam & $5.000 / 4$ ikat & 470 & 587.209 & 3.014 .925 \\
\hline \multicolumn{7}{r}{ Total } & & 2.487 .666 & 11.477 .035 \\
\hline
\end{tabular}

Sumber: Data primer diolah (2020)

\section{Biaya Usahatani}

Biaya usahatani sayuran adalah seluruh komponen biaya yang dikeluarkan oleh petani di Kelurahan Lambanapu dalam menjalankan usaha tani sayuran selama satu musim tanam. 


\section{ANALISIS PENDAPATAN USAHATANI SAYURAN DI KELURAHAN LAMBANAPU \\ KECAMATAN KAMBERA SUMBA TIMUR \\ Elsa Christin Saragih}

Total biaya yang dikeluarkan terdiri atas biaya tunai dan biaya yang diperhitungkan (biaya tidak tunai).

\section{Biaya Tunai (Out Of Pocket Cost)}

Dalam penelitian ini biaya tunai merupakan seluruh biaya dalam bentuk uang tunai yang dikeluarkan petani dalam proses usahataninya selama 1 musim tanam (MT). Biaya tunai meliputi biaya bibit, biaya pupuk (pupuk organik dan pupuk anorganik), biaya pestisida, biaya transportasi dan gaji tenaga kerja luar keluarga (TKLK). Biaya tunai usahatani sayuran di Kelurahan Lambanapu dapat dilihat pada Tabel 2.

Tabel 2. Rata-Rata Biaya Tunai Usahatani Sayuran di Kelurahan Lambanapu (per $1000 \mathrm{~m}^{2} / \mathrm{MT}$ )

\begin{tabular}{|c|c|}
\hline Uraian & Biaya/MT (Rp) \\
\hline 1. Bibit & 1.313 .791 \\
\hline $\begin{array}{l}\text { 2. Pupuk Organik } \\
\text { (Kandang) }\end{array}$ & 179.708 \\
\hline 3. Pupuk Anorganik & 268.322 \\
\hline 4. Pestisida & 90.285 \\
\hline 5. Sewa Lahan & 61.960 \\
\hline 6. Transportasi & 155.674 \\
\hline TOTAL & 2.069 .740 \\
\hline
\end{tabular}

Sumber: Data primer diolah (2020)

\section{Biaya Diperhitungkan}

Biaya yang diperhitungkan dalam penelitian ini terdiri dari biaya tenaga kerja dalam keluarga (TKDK) dan biaya penyusutan peralatan. Biaya diperhitungkan usahatani sayuran di
Kelurahan Lambanapu selama 1 musim tanam (MT) dapat dilihat pada Tabel 3.

Tabel 3. Rata-Rata Biaya Diperhitungkan Usahatani Sayuran di Kelurahan Lambanapu (per $1000 \mathrm{~m}^{2} / \mathrm{MT}$ )

\begin{tabular}{llc}
\hline \multicolumn{1}{c}{ Uraian } & Biaya/MT (Rp) \\
\hline 1. & Tenaga Kerja Dalam & 1.204 .229 \\
& Keluarga & \\
2. & Penyusutan Peralatan & 123.686 \\
\hline & Total & 1.327 .915 \\
\hline
\end{tabular}

Sumber: Data primer diolah (2020)

\section{Biaya Total}

Dalam penelitian ini biaya total merupakan jumlah dari biaya tunai dan biaya diperhitungkan yang dikeluarkan dalam melakukan kegiatan usahatani sayuran untuk 1 kali musim tanam (MT). Biaya total usahatani sayuran di Kelurahan Lambanapu dapat dilihat pada Tabel 4.

Tabel 4. Rata-Rata Biaya Total Usahatani Sayuran di Kelurahan Lambanapu (per $1000 \mathrm{~m}^{2} / \mathrm{MT}$ )

\begin{tabular}{lc}
\multicolumn{2}{c}{$\left(\right.$ per $\left.\mathbf{1 0 0 0} \mathbf{~ m}^{2} / \mathbf{M T}\right)$} \\
\hline Uraian & Biaya/MT (Rp) \\
\hline 1. Biaya Tunai & 2.069 .740 \\
2. Biaya Diperhitungkan & 1.327 .915 \\
\hline TOTAL & 3.397 .655 \\
\hline
\end{tabular}

Sumber: Data primer diolah (2020)

\section{Pendapatan Usahatani}

Analisis pendapatan dalam penelitian ini terbagi menjadi dua. Analisis yang pertama yaitu analisis pendapatan atas biaya tunai dan pendapatan atas biaya total. Analisis pendapatan usahatani sayuran di Kelurahan Lambanapu dapat di lihat pada Tabel 5 
Tabel 5. Rata-Rata Pendapatan Usahatani Sayuran di Kelurahan Lambanapu (per $1000 \mathrm{~m}^{2} / \mathrm{MT}$ )

\begin{tabular}{llc}
\hline \multicolumn{1}{c}{ Uraian } & Biaya/MT (Rp) \\
\hline 1. Penerimaan & 11.477 .035 \\
2. Biaya Tunai & 2.069 .740 \\
3. Biaya Diperhitungkan & 1.327 .915 \\
4. Biaya Total & 3.397 .655 \\
5. Pendapatan atas Biaya & 9.377 .295 \\
Tunai & \\
6. Pendapatan Atas Biaya & 8.079 .380 \\
& \\
\hline
\end{tabular}

Sumber: Data primer diolah (2020)

Total pendapatan terhadap biaya tunai yang didapat petani dari usahatani sayuran per $1000 \mathrm{~m}^{2}$ adalah $\mathrm{Rp}$. 9.377.295,-/MT/petani, dan untuk pendapatan atas biaya diperhitungkan sebesar Rp. 8.079.380,-/MT/petani. Pendapatan usahatani tersebut berada pada kategori memadai karena telah cukup untuk membeli seluruh sarana produksi selama proses usahatani. Berdasarkan hasil analisis tersebut usahatani sayuran di Kelurahan Lambanapu layak dikatakan berhasil karena jumlah penerimaan yang didapatkan sudah cukup membayar semua biaya tunai maupun yang diperhitungkan selama 1 musim tanam, bahkan masih menghasilkan selisih yang signifikan merupakan pendapatan petani.

\section{Efisiensi Usahatani}

Penetuan suatu usahatani apakah efisien atau tidak dapat dilihat dari keuntungan relatif dari usahatani sayuran yang dihitung dengan rumus analisis $\mathrm{R} / \mathrm{C}$ ratio. Nilai $\mathrm{R} / \mathrm{C}$ ratio adalah perbandingan antara penerimaan dengan biaya produksi. Dalam penelitian ini analisis rasio dibedakan menjadi dua yaitu perhitungan $\mathrm{R} / \mathrm{C}$ ratio atas biaya tunai dan perhitungan $\mathrm{R} / \mathrm{C}$ ratio atas biaya total. Analisis R/C ratio usahatani sayuran di Kelurahan Lambanapu dapat dilihat pada Tabel 6 berikut ini.

Tabel 6. Analisis Rasio Penerimaan Atas Biaya Usahatani Sayuran di Kelurahan Lambanapu (per $1000 \mathrm{~m}^{2} / \mathrm{MT}$ )

\begin{tabular}{lr}
\hline \multicolumn{1}{c}{ Uraian } & Biaya/MT (Rp) \\
\hline 1. Penerimaan & 11.477 .035 \\
2. Biaya Tunai & 2.069 .740 \\
3. Biaya Diperhitungkan & 1.327 .915 \\
4. Biaya Total & 3.397 .655 \\
5. R/C Biaya Ratio Atas & 5,53 \\
Biaya Tunai & \\
6. R/C Biaya Ratio Atas & 3,37 \\
& \\
\hline
\end{tabular}

Sumber: Data primer diolah (2020)

Berdasarkan Tabel 6 dapat dilihat bahwa nilai $\mathrm{R} / \mathrm{C}$ ratio atas biaya tunai sebesar 5,53. Hal ini berarti setiap Rp 1.000,- biaya yang dikeluarkan petani dalam menjalankan usahatani sayuran akan memberikan penerimaan sebesar Rp 5.530. Sedangkan nilai $\mathrm{R} / \mathrm{C}$ ratio atas biaya total diperoleh sebesar 3,37 yang mengindikasikan bahwa setiap Rp. 1.000,- atas biaya keseluruhan yang dikeluarkan akan memberikan penerimaan sebesar $\mathrm{Rp} 3.370,-$ kepada petani pengusaha sayuran di Kelurahan Lambanapu. 


\section{KESIMPULAN DAN SARAN}

Berdasarkan hasil analisis pendapatan menunjukkan bahwa pendapatan petani sayuran di Kelurahan Lambanapu selama satu musim tanam terakhir sudah menguntungkan. Pendapatan usahatani petani atas biaya tunai per $1000 \mathrm{~m}^{2}$ pada musim tanam Mei-Juni 2020 mencapai Rp. 9.377.295,/MT/petani.

Berdasarkan hasil analisis efisiensi kegiatan usahatani sayuran di Kelurahan Lambanapu sudah efisien karena $\mathrm{R} / \mathrm{C}$ rasio lebih dari satu $(\mathrm{RC}>1)$, yaitu sebesar 5,53 untuk biaya tunai dan 3,37 untuk biaya yang diperhitungkan. Kegiatan usahatani sayuran yang dilakukan oleh petani ini layak untuk dikembangkan karena menguntungkan secara ekonomis.

\section{DAFTAR PUSTAKA}

Arief, A. (1990). Hortikultura. Yogyakarta: Budi Offset.

Azzura, D., Marsudi, E., \& Usman, M.
(2017). Analisis Pendapatan Usahatani Sayur-Sayuran dan Faktor-Faktor yang Mempengaruhinya di Kecamatan Darussalam Kabupaten Aceh Besar. Jurnal Ilmiah Mahasiswa Pertanian Unsyiah, 2(3), 92-105.

BPS. (2018). Survei Struktur Ongkos Usaha Tanaman Hortikultura. Jakarta: Badan Pusat Statistik.

Edi, S., \& Bobihoe, J. (2010). Budidaya Tanaman Sayuran. Jambi: Balai Pengkajian Teknologi Pertanian (BPTP) Jambi.

Hermina, \& Prihatini, S. (2016). Gambaran Konsumsi Sayur dan Buah Penduduk Idalam Gambaran Konsumsi Sayur dan Buah Penduduk Indonesia dalam Konteks Gizi Seimbang: Analisis Lanjut Survei Konsumsi Makanan Individu ( SKMI ) 2014. Buletin Penelitian Kesehatan, 44(3), 205218.

Normansyah, D., Rochaeni, S., \& Humaerah, A. D. (2014). Analisis Pendapatan Usahatani Sayuran di Kelompok Tani Jaya, Desa Ciaruteun Ilir, Kecamatan Cibungbulang Kabupaten Bogor. Jurnal Agribisnis, 8(1), 29-44.

Soekartawi, A Soeharjo, John L, B. H. (1985). Ilmu Usahatani Dan Penelitian Untuk Pengembangan Petani Kecil. Jakarta: UI Press. 